\title{
A religião na formação social de jovens no município de Santa Teresa-ES
}

\author{
Gleides Pulcheira Paixão \\ Ronaldo De Paula Cavalcante \\ Marcus Vinicius Sandoval Paixão \\ Instituto Federal do Espírito Santo
}

\section{Resumo}

Objetivou-se analisar o efeito da religião na formação social de jovens do ensino médio das escolas de Santa Teresa, ES. A pesquisa foi feita com jovens entre 14 e 18 anos de idade, e nas igrejas católica, evangélica e espírita, do município. Foram feitas entrevistas com os líderes religiosos, utilizando-se questionários, para conhecer princípios, problemas vivenciados, atuação, mudanças presenciadas, contribuição e participação na formação dos jovens, e nas escolas com alunos regularmente matriculados. A partir dos dados coletados, podemos conceber como "altíssima" a influência que a igreja possui na formação social dos jovens das escolas de ensino médio do município de Santa Teresa, e podemos considerar como "alta" a aceitação de que todas as linhas religiosas influenciam na formação social dos jovens.

Palavras-chave: Igreja. Escola. Ensinamentos. Religiosidade. Educação.

\section{Religion in the social training of youth in the municipality of Santa Teresa-ES}

\section{Abstract}

The objective of this study was to analyze the effect of religion on the social formation of high school youth in Santa Teresa, ES schools. The research was done with young people between 14 and 18 years old and in the Catholic, Evangelical and Spiritist churches of the municipality. Interviews were conducted with religious leaders, using questionnaires, to learn about principles, problems experienced, actions, changes observed, contribution and participation in the training of young people, and in schools with regularly enrolled students. From the data collected, we can consider as a "very high" influence that the church has in the social formation of the young people of the high schools of the municipality of Santa Teresa, as we can consider as "high" the 
acceptance that all religious lines influence in the social formation of young people.

Keywords: Church. School. Teachings. Religiosity. Education.

\section{Religión en la formación social joven en el municipio de Santa Teresa-ES}

\section{Resumen}

Se objetivó analizar el efecto de la religión en la formación social de jóvenes de la enseñanza media de las escuelas de Santa Teresa, ES. La investigación fue hecha con jóvenes entre 14 y 18 años y en las iglesias católica, evangélica y espírita, del municipio. Se realizaron entrevistas con los líderes religiosos, utilizando cuestionarios, para conocer principios, problemas vivenciados, actuación, cambios presenciados, contribución y participación en la formación de los jóvenes, y en las escuelas con alumnos regularmente matriculados. A partir de los datos recolectados, podemos considerar como "altíssima" influencia que la iglesia posee en la formación social de los jóvenes de las escuelas de enseñanza media del municipio de Santa Teresa, como podemos considerar como "alta" la aceptación de que todas las líneas religiosas influencian en la formación social de los jóvenes.

Palabras clave: Iglesia. Escuela. Enseñanzas. Religiosidad. Educación.

\section{Introdução}

Com a demanda e exploração religiosa em todos os cantos do globo terrestre, algumas crenças passam a ser interrogadas se o objetivo da mesma é educacional ou comercial. No âmbito religioso, quando se define realmente o papel das igrejas, observa-se que um trabalho de conscientização, estudo educacional, formação social e reaproximação com Deus é ponto de partida para a grande massa de instituições religiosas que estão preocupadas na formação do cidadão.

Ao observarmos nossos jovens, carregando um grande número de problemas advindos de questões diversas que ocorrem em seu cotidiano, e ao mesmo tempo em que vimos outros jovens com condutas exemplares, perguntamo-nos o que poderia estar acontecendo, por existir tamanhas diversidades.

As diversidades educacionais encontradas, as condutas sociais e a necessidade de mudança interior são problemas detectados em um contexto macro. A inserção da religião no cotidiano dos jovens, como forma de mudança, também se constitui um problema, quando observamos que a mudança interior nem sempre obtém o sucesso esperado devido à existência de limitações pessoais que ocorrem quando da aceitação de novos paradigmas propostos e que divergem totalmente daqueles que são seguidos naquele momento. 
Transformar indivíduos que possuem formação social duvidosa não é tarefa para uma única instituição. A família, o convívio externo, a escola e outros talvez não possuam tanta força nessa transformação como a igreja, que ao incutir a fé em um ente superior pode fazer os milagres que o mundo moderno não acredita que possam existir.

Face à diversidade religiosa encontrada hoje em todo o globo terrestre, com várias linhas religiosas atuando na formação de conduta de jovens, fazem-se necessário estudos sobre a atuação destas na formação social dos jovens. É visto que cada uma das diversas linhas religiosas existentes procura incutir na cabeça dos cidadãos, que as frequentam, um pensamento diferente, ou seja, cada uma procura um paradigma que a satisfaz e que, no pensamento daqueles que acreditam, pode alcançar a plena realização a partir do seu segmento e do cumprimento das regras criadas por um ser humano, que diz ser reverenciada pelas escritas que seguem, e que foram criadas por alguém muito tempo atrás.

Ancorado em diversas teorias que se leem, escutadas ou faladas, a religião apresenta para quem as cultiva uma melhora de diversas formas diferentes, melhoras essas que podem ser observadas na vida de todos aqueles que creem e que se dedicam a algum tipo de religião.

Essas formas diferentes justificam a ideia que, de alguma forma, elas podem estar interferindo na formação de jovens, acrescentando-lhes algo que ainda não foi decifrado.

O pensamento de que aqueles que possuem uma educação religiosa partida da juventude, tem comportamento diferenciado daqueles que não possuem na família o credo da religião, é fator a se considerar quando se fala de inclusão social ou formação de jovens, justificando o interesse em pesquisar até que ponto isso é verdade. A formação social dada aos jovens pode estar relacionada com a presença ou não da religião na vida de cada criança. A inserção da religião durante o período de crescimento pode ser fundamental para que o jovem construa sua personalidade com caráter e honestidade.

Dessa afirmação surgiu a necessidade de pesquisar até que ponto a religião pode estar ligada à formação social do jovem, na construção de sua personalidade, conduta e caráter construídos a partir de dogmas exigidos pela sociedade contemporânea, assim como, em que atributos a religião atua diretamente, transferindo para o jovem que frequenta alguma religião seus princípios e seus paradigmas. Considerando essas afirmativas, objetivou-se 
nesta pesquisa analisar o efeito da religião na formação social de jovens do ensino médio das escolas do município de Santa Teresa, ES.

\section{Metodologia}

A pesquisa foi feita com jovens entre 14 e 18 anos de idade, que cursam o ensino médio do município de Santa Teresa, ES, nas quatro escolas e nas igrejas (católica, evangélica) e centro espíritas existentes no município.

O município de Santa Teresa se localiza na zona serrana do Estado do Espírito Santo, sendo que sua parte mais alta fica a 675 metros de altitude. A sede municipal, a 665 metros de altitude, tem sua posição geográfica determinada pelo Paralelo de $20^{\circ}$ 6' $02^{\prime \prime}$ de latitude, tem sua posição geográfica de $40^{\circ}$ 37' 47" de longitude oeste. Apresenta na parte Sul um clima mais frio e na parte Norte um clima tropical quente. A temperatura média anual é $18^{\circ} \mathrm{C}$ e a precipitação pluviométrica média anual de $2000 \mathrm{~mm}$ (INCAPER, 2011).

O município possui aproximadamente 21.200 habitantes, sendo aproximadamente 11.200 habitantes na sede e 10.000 no interior.

$\mathrm{Na}$ pesquisa de campo, foram visitadas algumas casas religiosas, observando o funcionamento prático, suas pregações e ensinamentos, com o objetivo de analisar seus comportamentos. Foram feitas entrevistas com os líderes religiosos, utilizando-se questionários qualitativos, com vistas a conhecer os princípios, os problemas vivenciados, a atuação de cada igreja e seus objetivos, as mudanças presenciadas, a contribuição e a participação na formação dos jovens, assim como, questionários quantitativos nas escolas de ensino médio com alunos regularmente matriculados, empregando as variáveis e quesitos que quantifiquem o grau de participação da igreja no processo de formação social do jovem que frequenta o ensino médio nas escolas do município de Santa Teresa.

A partir da análise dos dados da pesquisa de campo, adotamos uma abordagem qualitativa e quantitativa, que reúne uma série de técnicas interpretativas que procuram descrever, decodificar, traduzir e de alguma forma chegar a um significado de forma natural no mundo social.

A abordagem da amostra foi probabilística e representativa, sendo a coleta de dados feita por meio de questionários e a análise dos dados por intermédio do percentual de respostas para cada item, de modo a garantir a precisão dos resultados e evitar distorções na análise e interpretação dos dados. 
$\mathrm{Na}$ pesquisa de campo, adotamos como procedimento, o contato direto com o fenômeno de estudo, com procedimentos metodológicos estabelecidos.

Nas entrevistas, a interrogação direta das pessoas cujo comportamento religioso se deseja conhecer foi feita solicitando informações de um grupo significativo de pessoas acerca do problema estudado para, em seguida, mediante análise do coletado, se obterem as conclusões correspondentes aos dados coletados.

A pesquisa foi aplicada pelo próprio pesquisador, por contato direto, utilizando todas escolas existentes no município de Santa Teresa, sendo elas: IFES Campus Santa Teresa, Escola Pinto Coelho, Escola Polivalente Frederico Pretti, Escola São Francisco de Assis.

Entre as igrejas selecionadas, procuramos as de maior participação pública, entre as de linha Católica, Protestante, subdividindo em: Luteranos, Batistas, Assembleia de Deus, Presbiterianos, Adventista, Universal, Maranata e Pentecostal, e Centros Espíritas, subdividindo-se em Kardecismo e Umbanda.

A investigação de campo ocorreu durante o segundo semestre de 2016, nas escolas de ensino médio e igrejas do município de Santa Teresa, ES.

Nesta pesquisa, trabalharemos com uma amostra aproximada de $70 \%$ da população, conforme segue: IFES Campus Santa Teresa - 450 alunos; Escola Pinto Coelho - 648 alunos; Escola Polivalente Frederico Pretti - 309 alunos; Escola São Francisco de Assis - 72 alunos.

Foram realizados mil questionários como amostra, em uma população de 1.351 alunos existentes. A amostra das instituições religiosas foi feita pelo próprio pesquisador e eleita entre as igrejas existentes no município de Santa Teresa. A amostra foi aleatória simples de 35\% da população dessas igrejas, compostas de: Igrejas Católicas - total de igrejas - 9; Igrejas Protestantes total de igrejas - 16; Centros Espíritas - total de centros - 3.

Totalizamos 450 questionários, em uma população aproximada de 1.280 pessoas, que frequentam regulamente as igrejas selecionadas para esta pesquisa.

As escolhas se deram por sua importância e envolvimento no processo, devendo considerar a capacidade de resposta existente em cada igreja e seus participantes. Os dados foram coletados por meio de questionários e entrevistas, elaborados para os jovens do ensino médio e líderes religiosos que frequentam as igrejas citadas nesta pesquisa.

Os questionários aplicados aos alunos do ensino médio apresentaram perguntas fechadas, que são aquelas que exibiram respostas fixas, como as 
de múltipla escolha. O questionário aplicado aos líderes religiosos foi de questões abertas, possibilitando variações de respostas.

As perguntas elaboradas para os alunos atenderam a uma sequência criativa, na qual o entrevistado evolui em seu raciocínio no caminhar das respostas, de modo que a resolução de uma questão ajuda na resposta da sequente, com uma lógica que vincula os dados com as perguntas e com a proposta da pesquisa.

Nos questionários nas escolas de ensino médio, utilizamos as variáveis e quesitos como participação, importância, interferência, mudança, influência e ajuda que quantifiquem o grau de participação da igreja no processo de formação social do jovem do ensino médio das escolas do município de Santa Teresa.

As entrevistas com líderes das igrejas partiram de uma sequência lógica de perguntas, vinculando-as à proposição da pesquisa, procurando extrair o máximo de conhecimentos que mostrem como funcionam os conceitos aplicados nas igrejas, sendo eles: os princípios, os problemas, a atuação de cada igreja, seus objetivos, as mudanças presenciadas, a contribuição e a participação na formação dos jovens com os resultados obtidos a partir das atividades desenvolvidas em seu cotidiano.

A partir da pesquisa de campo, podemos confrontar os dados, considerando as variáveis previstas, e analisar probabilisticamente qual o grau de influência a igreja possui na formação social do jovem no município de Santa Teresa.

Pelas características metodológicas desta pesquisa, algumas análises estatísticas não foram utilizadas, privilegiando os métodos qualitativos de investigação exploratória. Por sua vez, também utilizamos alguns dados quantitativos extraídos dos questionários aplicados aos alunos.

Os dados desta pesquisa foram processados e organizados levando-se em consideração as variáveis intervenientes, que foram: idade, sexo, local de residência, tipo de escola, poder aquisitivo e nível educacional familiar, confrontando-os com dados coletados a partir dos dados de participação, importância, interferência, mudança, influência e ajuda, que quantificam o efeito da igreja no processo de formação social do jovem do ensino médio.

Os dados coletados na pesquisa exploratória, feita nas igrejas do município, foram processados por categoria e número de citações pelos entrevistados, de modo a organizá-las de forma quantitativa, relacionando-as ao quesito formação social do jovem, de modo a descartar as respostas que não se relacionavam com o tema. 
Nos questionamentos aos líderes religiosos, observamos citações aos problemas relacionados a questões familiares, onde a igreja participa efetivamente na conscientização, formação, orientação e assistência desses jovens.

\section{Análise e discussão dos resultados}

De acordo com os dados coletados sobre a religião dos alunos que participaram da pesquisa, foi observado o seguinte resultado (Tabela 1).

Tabela 1 - Dados religiosos aplicados aos alunos.

\begin{tabular}{lcccc}
\hline & Católica & Protestante & Espírita & Nenhuma \\
\hline Religião dos alunos (\%) & 80 & 13,5 & 2,8 & 3,7 \\
Religião dos pais (\%) & 78 & 11,6 & 2,8 & 7,6 \\
Frequência à igreja (\%) & 87 & 100 & 100 & - \\
\hline
\end{tabular}

Observa-se que a religião católica predomina no município, mostrando a força que essa religião pode ter sobre os jovens. Os ensinamentos da igreja católica podem parecer como de fundamental importância na formação social dos jovens que a frequentam, interferindo diretamente no que se refere aos atributos atitudinais a serem construídos.

Segundo o IBGE (2010), "o catolicismo romano aparece com 64,6\%, o protestantismo aparece com $22,2 \%$, espiritismo $2 \%$, sem religião $8 \%$ e outras religiões aparece com 3,2\%".

De acordo com o Portal Sua escola (2016):

O catolicismo ainda é a maior força entre as religiões no Brasil, levando sua fé, suas doutrinas, liturgia e teologia, com princípios éticos e comportamentais, criando um conceito de fé básico para os brasileiros. Entre as 5 maiores religiões brasileiras, o Catolicismo se destaca com a preferência de $65 \%$ da população brasileira.

Consideramos como catolicismo a fé pregada pela Igreja Católica, incluindo aí tanto a Igreja Apostólica Romana, quanto a Igreja Católica Brasileira e a Igreja Ortodoxa. Como a principal das religiões do Brasil, o catolicismo está presente no país desde sua colonização, introduzido pelos jesuítas que acompanharam os colonizadores portugueses. O Brasil é 
considerado o maior país do mundo em número de católicos, trazendo muitas tradições e tendo muitos centros de peregrinação.

Como segunda das religiões do Brasil, podemos considerar os Evangélicos, que reúne os Protestantes e suas diversas versões, como a Igreja Presbiteriana, a Igreja Luterana, a Igreja Batista, Maranata, Assembleia de Deus a Igreja Metodista dentre outras. O Protestantismo é um dos principais segmentos do Cristianismo, sendo um movimento originário da Europa Central, no século XV, criado como reação contrária às doutrinas e ações do Catolicismo Romano Medieval.

Na terceira posição está o Espiritismo, uma doutrina codificada por Hippolyte Léon Denizard Rivail, um pedagogo francês que utilizou o pseudônimo de Allan Kardec para divulgar a doutrina. O Espiritismo, segundo seus próprios seguidores, não é exatamente uma religião, mas sim uma fusão de filosofia, de religião e de ciência, buscando estudar e compreender o universo, não apenas em seu lado científico, mas também no lado moral e ético. A Umbanda e o Candomblé são as religiões mais heterodoxas do Brasil, sendo uma evolução das crenças africanas, trazidas na época da escravatura. Muitos de seus membros se consideram também espíritas, havendo maior liberalização com relação a costumes e ritos, sem uma centralização maior dos seus dogmas (PORTAL SUA ESCOLA, 2016).

Podemos observar que não só a religião católica possui poderes sobre os jovens, as igrejas evangélicas aparecem como religiões emergentes, com uma grande quantidade de fiéis e cultos que atuam decisivamente na construção dos atributos atitudinais dos jovens, de forma que também as igrejas evangélicas podem agir de modo marcante na formação social dos jovens. Completando esse universo, temos os adeptos das religiões espíritas, que em um universo menor que os outros segmentos, também possuem uma forte atuação na formação dos jovens, com seus dogmas e crenças que operam de forma marcante nos adeptos a esta religião.

Segundo Novaes (2004), "no momento atual, surge também a possibilidade de, entre os sem religião, estarem jovens que se aproximam da umbanda, do candomblé ou do espiritismo". Ao falar sobre as reuniões mediúnicas, sempre se pergunta a respeito de seu futuro frente à escalada pentecostal.

Para Novaes (2004):

Não há como negar que o crescimento pentecostal disputa "nas bases" com as religiões afro-brasileiras. Não é por acaso, diga-se de passagem, que a 
neopentecostal Igreja Universal do Reino de Deus elege entidades e orixás como seus adversários mais poderosos. O exorcismo - ali denominado de libertação - pressupõe a crença no poder do inimigo sendo preciso não esquecer que, certamente, muitos jovens entrevistados, como em gerações anteriores, continuam se definindo como católicos, sem deixar de ir a centros espíritas e a terreiros. Este fenômeno revela estratégias de apresentação social frente aos preconceitos e perseguições sofridas pelos adeptos das religiões afro-brasileiras ao longo da história, mas revela também sentimentos de "duplo pertencimento" que fazem com que um pai ou uma mãe de santo possam dizer, sem constrangimento: "sou católica e da umbanda" ou "sou católica e do santo" para além da onda evangélica - neste momento em que "ser católico" deixou de ser um requisito socialmente obrigatório, pode-se estar em vigor um novo expediente, frequentadores dos centros espíritas, da umbanda e do candomblé podem estar engrossando as fileiras dos "sem religião".

Perguntado sobre religião aos alunos, obtivemos o seguinte resultado (Tabela 2).

Tabela 2 - Dados sobre a religião aplicados aos alunos.

\begin{tabular}{lcc}
\hline Perguntas & Sim (\%) & Não (\%) \\
\hline Você acha que a igreja pode lhe ajudar em alguma coisa & 95,7 & 4,3 \\
Você acha que a igreja pode mudar a vida de alguém & 92,1 & 7,9 \\
Você acha que a igreja pode conduzir os caminhos de alguém & 90,5 & 9,5 \\
Você conhece alguém que mudou sua conduta após entrar & 74 & 26 \\
para a igreja & 92,2 & 7,8 \\
$\begin{array}{l}\text { Eles permanecem na igreja até hoje } \\
\text { Você recomendaria a um amigo que estivesse com problemas }\end{array}$ & 85,7 & 14,3 \\
$\begin{array}{l}\text { sociais que procurasse uma igreja para pedir ajuda } \\
\text { Você acha que a igreja pode ajudar na boa formação dos }\end{array}$ & 94,6 & 5,4 \\
jovens & & \\
\hline
\end{tabular}

\section{Questionário dirigido aos líderes católicos do município de Santa Teresa:}

- Número de membros participantes nos trabalhos religiosos - 1.300 pessoas em 52 comunidades com igrejas, destes aproximadamente 300 jovens.

- Missão - Evangelizar, anúncio do evangelho para a promoção humana. 
- Maiores problemas - familiar, crise existencial e vícios.

- Tratamento dado a essas pessoas - ouvir, aconselhar e orientar.

- Índice de recuperação - 70\%.

- Quem trabalha com os problemas - pastoral familiar.

- Essas pessoas ainda estão na igreja - sim.

- Contribuição financeira - contribuição voluntária.

- Participação da igreja na formação social dos jovens que a frequentam - por meio de encontros, catequese, palestras, visitas e encontros familiares, esporte.

- Participação da família na vida religiosa do jovem - parcial.

Perguntados sobre como a religião católica participa nesse processo de transformação do jovem, observamos que nove itens foram citados pelos entrevistados. Dos entrevistados, 49\% mencionaram educação, 40\% conscientização, 34\% aconselhamento, 29\% integração, 22\% encontros, $11 \%$ formação, $11 \%$ resgate de valores, $7 \%$ sociabilidade e $7 \%$ trabalhos religiosos (nesse item, algumas pessoas disseram mais de um quesito).

Quando perguntamos quais os maiores problemas trazidos para a igreja católica pelos jovens, foram citados quatro itens para esse quesito, sendo que problemas familiares receberam um índice de $67 \%$ de indicações, 49\% vícios, $14 \%$ desorientação e $7 \%$ sociabilização (nesse item, algumas pessoas mencionaram mais de um quesito).

- Houve mudanças de procedimentos, após entrar para a igreja $100 \% \operatorname{sim}$.

- A igreja teve importância na sua formação social - 100\% sim.

- A participação da igreja influenciou na educação de seus filhos $10 \% \operatorname{sim}$.

Perguntados quais os principais ensinamentos adquiridos na igreja católica, quatorze itens foram citados para esse quesito, recebendo um índice de $56 \%$ o item respeito, $29 \%$ união familiar, $29 \%$ visão geral do ser humano, $27 \%$ solidariedade, $15 \%$ religiosidade, $15 \%$ amor, $14 \%$ consideração ao próximo, 14\% educação, 9\% relacionamento, 9\% honestidade, $7 \%$ fidelidade, $7 \%$ integridade moral, $5 \%$ sociabilidade, $5 \%$ igualdade (nesse item, algumas pessoas mencionaram mais de um quesito).

A respeito de como você vê a atuação da igreja católica na formação social dos jovens, $91 \%$ dos entrevistados consideraram que a igreja católica está fazendo pouco em relação ao público total a ser atingido e poderia fazer 
mais, o trabalho feito na igreja é muito bom, porém atinge um público muito pequeno, $9 \%$ classificaram o trabalho satisfatório.

Acerca dos problemas detectados nos jovens que conseguiram alguma mudança ao entrarem para a igreja católica, entre os $88 \%$ dos entrevistados que responderam sim na pergunta anterior, obtivemos os índices de $67 \%$ para vícios, 33\% de problemas familiares, 11\% crise existencial, 11\% relacionamento, $9 \%$ participação comunitária, 7\% falta de fé, 3\% prostituição (nesse item, algumas pessoas citaram mais de um quesito).

Perguntados sobre a conduta dos jovens aos líderes da religião católica, obtivemos o seguinte resultado (Tabela 3):

Tabela 3 - Dados sobre a religião católica aplicados aos líderes.

\begin{tabular}{lcc}
\hline Perguntas & Sim (\%) & Não (\%) \\
\hline Presenciou mudanças de conduta de jovens, após entrar para a igreja & 78 & 22 \\
$\begin{array}{l}\text { Possui conhecimento de participante que mudou, após entrar para } \\
\text { a igreja }\end{array}$ & 88 & 12 \\
$\begin{array}{l}\text { Você acha que a igreja é a instituição que mais contribui para a } \\
\text { formação }\end{array}$ & 40 & 60 \\
Todas as religiões contribuem para a formação social do jovem & 89 & 11 \\
\hline
\end{tabular}

\section{Questionário dirigido aos líderes da religião espírita do município de Santa Teresa:}

- Número de membros participantes nos trabalhos religiosos aproximadamente 100 .

- Missão - promover o amor, caridade e fé entre os homens.

- Maiores problemas - problemas pessoais.

- Tratamento dado a essas pessoas - individual com orientação e mostrar a verdade.

- Índice de recuperação - 98\% dos que aceitam a verdade.

- Quem trabalha com os problemas - os membros da casa espírita.

- Essas pessoas ainda estão na igreja - entre 60\% a 70\% sim.

- Contribuição financeira - a manutenção é dividida entre os médios, não há cobrança dos que procuram a casa para ajuda.

- Participação da igreja na formação social dos jovens que a frequentam - mostrar o caminho respeitando o livre-arbítrio.

- Participação da família na vida religiosa do jovem - integral.

- Número de filhos dos participantes que têm conduta duvidosa desconhecido. 
Perguntados acerca de como a religião espírita participa nesse processo de transformação do jovem, observamos que sete itens foram citados pelos entrevistados, sendo que $46 \%$ dos entrevistados mencionaram formação espiritual, 20\% aconchego espiritual e emocional, 20\% aconselhamento, 14\% preparo para a vida, 11\% orações, $11 \%$ equilíbrio (algumas pessoas citaram mais de um quesito).

Quando perguntamos quais os maiores problemas trazidos para o centro espírita pelos jovens, oito itens foram citados para esse quesito, recebendo um índice de 37\% para os problemas familiares, 26\% vícios, $26 \%$ desvios de conduta, $20 \%$ carência, $17 \%$ doenças físicas, $14 \%$ sentimental, $11 \%$ insegurança, $11 \%$ relacionamento (nesse item, algumas pessoas mencionaram mais de um quesito).

- Houve mudanças de procedimentos, após entrar para a religião $100 \%$ sim.

- A religião teve importância na sua formação social - 100\% sim.

- A participação da casa espírita influenciou na educação de seus filhos $-100 \%$ sim.

A respeito de quais os principais ensinamentos adquiridos na casa espírita, doze itens foram citados para esse quesito, recebendo um índice de $34 \%$ o item relacionamento, $34 \%$ conduta, $20 \%$ moral, $20 \%$ intelectual, $17 \%$ educação, 17\% cooperação, 14\% diálogo, 14\% equilíbrio, 12\% religiosidade, $12 \%$ humildade, $9 \%$ simplicidade, $6 \%$ comportamento (nesse item, algumas pessoas mencionaram mais de um quesito).

Ao indagarmos como você vê a atuação da religião espírita na formação social dos jovens, $91 \%$ dos entrevistados consideraram que o trabalho feito na casa espírita é excelente. Quando a família participa junto, a formação é melhor, com melhoria na conduta, e resgate de valores, 9\% consideraram que a religião pode fazer mais.

Acerca dos problemas detectados nos jovens que conseguiram alguma mudança ao entrarem para a casa espírita, 20\% dos entrevistados responderam problemas de conduta, 20\% insegurança, 20\% relacionamento, $20 \%$ familiar, $12 \%$ falta de humildade, $8 \%$ falta de Deus.

Perguntados sobre a conduta dos jovens aos líderes da religião espírita, obtivemos o seguinte resultado (Tabela 4): 
Tabela 4 - Dados sobre a religião espírita aplicados aos líderes.

\begin{tabular}{lcc}
\hline Perguntas & Sim $(\%)$ & Não (\%) \\
\hline Presenciou mudanças de conduta de jovens, após entrar para a igreja & 77 & 23 \\
$\begin{array}{l}\text { Possui conhecimento de participante que mudou, após entrar para } \\
\text { a igreja }\end{array}$ & 89 & 11 \\
$\begin{array}{l}\text { Você acha que a igreja é a instituição que mais contribui para a } \\
\text { formação }\end{array}$ & 49 & 51 \\
Todas as religiões contribuem para a formação social do jovem & 94 & 06 \\
\hline
\end{tabular}

\section{Questionário dirigido aos líderes da religião protestante do município de Santa Teresa:}

- Número de membros participantes nos trabalhos religiosos aproximadamente 280 .

- Missão:

- Igreja Presbiteriana - pregar o evangelho da salvação.

- Igreja Luterana - levar Cristo para todos.

- Igreja Adventista - pregação do evangelho para a volta de Jesus.

- Igreja Maranata - evangelizar e mostrar o caminho que Deus propôs ao ser humano.

- Igreja Assembleia de Deus - aceitação de Jesus como o único salvador, acreditando em sua eminente volta.

- Igreja Batista - transformar vidas em nome de Jesus.

- Igreja Universal - a salvação pela fé em Cristo, pela existência de um só Deus e a volta de Jesus.

- Igreja Pentecostal - levar o Evangelho do Reino por toda a terra.

- Maiores problemas - familiar, conjugais, falta de amparo espiritual, questões financeiras e incertezas da vida.

- Tratamento dado a essas pessoas - instruções, orientações, aconselhamentos, atendimento especial, apoio pastoral.

- Índice de recuperação:

- Igreja Presbiteriana - 25\%, Igreja Luterana - 50\%, Igreja Adventista - 60\%, Igreja Maranata - 80\% a 90\%, Igreja Assembleia de Deus - 40\%, Igreja Batista $-80 \%$ a 90\%, Igreja Universal - 80\%, Igreja Pentecostal - 75\%.

- Quem trabalha com os problemas - na igreja Adventista, Maranata e Universal todo o corpo da igreja, nas outras é o pastor quem atua. 
Essas pessoas ainda estão na igreja - sim para todas as igrejas.

- Contribuição financeira - apenas a igreja Batista citou o dízimo de $10 \%$, todas as outras mencionaram que o dízimo é voluntário.

- Participação da igreja na formação social dos jovens que a frequentam - por meio de aconselhamento, motivação, capacitação, educação religiosa, envolvimento, orientação espiritual e conscientização.

- Participação da família na vida religiosa do jovem - integral.

- Número de filhos dos participantes que têm conduta duvidosa poucos, os que frequentaram a igreja mudaram sua conduta, se recuperaram e ainda estão na igreja.

Perguntados acerca de como a religião protestante participa nesse processo de transformação do jovem, doze itens foram citados pelos entrevistados sendo que 34\% dos entrevistados mencionaram que a igreja participa com orientação, 26\% formação espiritual, 22\% visitas, $20 \%$ estudos, $16 \%$ programas sociais, $16 \%$ aconselhamentos, $10 \%$ conscientização, $10 \%$ mostrando o caminho, 8\% fornecendo amizades, 8\% oração, 7\% apoio moral e $5 \%$ transmitindo amor (nesse item, algumas pessoas citaram mais de um quesito).

Perguntados a respeito de quais os maiores problemas trazidos para a igreja protestante pelos jovens, oito itens foram citados para esse quesito, recebendo um índice de 50\% para os problemas familiares, 34\% vícios, 15\% influências negativas, $15 \%$ ausência de Deus, $12 \%$ falta de instrução, 10\% relacionamento, 10\% desvios de conduta, 3\% prostituição (algumas pessoas mencionaram mais de um quesito).

- Houve mudanças de procedimentos, após entrar para a igreja $100 \%$ sim.

- A igreja teve importância na sua formação social - 100\% sim.

- A participação da igreja influenciou na educação de seus filhos $97 \%$ sim.

Perguntados acerca de quais principais ensinamentos adquiridos na igreja protestante, doze itens foram citados. Recebeu um índice de 48\% a citação do item educação, 35\% princípios morais, 35\% comportamento, 25\% relacionamento, $25 \%$ honestidade, $22 \%$ religiosidade, $15 \%$ ética, $15 \%$ justiça, $9 \%$ fidelidade, 6\% respeito, 5\% doutrina e 3\% formação do caráter (algumas pessoas mencionaram mais de um quesito). Ao indagarmos como você vê a atuação da religião protestante na formação social dos jovens, $88 \%$ dos 
entrevistados consideraram que o trabalho feito na igreja protestante é muito bom, $12 \%$ classificaram que ainda pode melhorar.

A respeito dos problemas detectados nos jovens que conseguiram alguma mudança, ao entrarem para a igreja protestante, entre os itens mencionados obtivemos $58 \%$ de citações para o quesito vícios, $25 \%$ familiar, $13 \%$ conduta, $7 \%$ problemas financeiros, $4 \%$ falta de Deus, $3 \%$ falta de formação, $2 \%$ problemas sociais (nesse item, algumas pessoas apontaram mais de um quesito). Ao perguntarmos sobre a conduta dos jovens aos líderes da religião protestante, obtivemos o seguinte resultado (Tabela 5):

Tabela 5 - Dados sobre a igreja protestante aplicados aos líderes.

\begin{tabular}{lcc}
\hline Perguntas & Sim $(\%)$ & Não $(\%)$ \\
\hline Presenciou mudanças de conduta de jovens, após entrar para a igreja & 90 & 10 \\
Possui conhecimento de participante que mudou, após entrar para & 79 & 21 \\
a igreja & & \\
Você acha que a igreja é a instituição que mais contribui para a & 75 & 25 \\
formação & 73 & 27 \\
Todas as religiões contribuem para a formação social do jovem & 73 \\
\hline
\end{tabular}

A religiosidade, além de se tratar de um aspecto relevante para os entrevistados, parece ocupar importante papel na estruturação da família, responsável pela humanização do indivíduo, auxiliando-o na construção de sua personalidade. Também se revela como importante fonte divulgadora de informações quanto aos aspectos negativos do uso de drogas. Assim, a religiosidade teria uma função ampla, permeando entre os demais fatores protetores citados, como ocorre para a família, informação e perspectivas de futuro.

Observamos que os diversos problemas que invadem o jovem em seu cotidiano, e interferem na sua formação, passam por diversas etapas de sua vida, inclusive a fase religiosa. É notório que a religião católica com sua grande maioria de adeptos teria papel fundamental para modificar esse processo, porém o que se percebe é um crescimento acentuado de outras religiões.

Segundo Diniz (1999):

...a doutrina Cristã como a grande mentora na formação religiosa dos estudantes, onde, o principal suporte para essa formação é o Culto/ 
Doutrina da Igreja Católica, comprova o mais destacado trajeto sóciopolítico-ideológico-institucional-religioso da nossa população, desde os tempos coloniais. Encontra sinais de um grau significante de mobilidades, experiências outras e socializações religiosas várias, que ajudam a realçar toda a complexidade cultural em nível de manifestações, experiências e socializações religiosas, graúdas de multiplicidades e intensidades híbridas doutrinárias e práticas de cultos religiosos alternativos; de protesto; populares; optativos; profanos; mágicos; misteriosos; esotéricos; de outras tradições e rituais originalmente longínquos a nossa caracterização ocidental.

Dom Geraldo Majella Agnelo faz citações sobre religiosidade e juventude, entre elas, ele menciona que ao enfraquecer a juventude com os vícios aumentam as chances da vitória externa. "Os vícios geram dependência e moleza, enquanto que as virtudes produzem o heroísmo. Conseguir transformar os jovens é papel da igreja católica, trabalhando todos os problemas trazidos pelos jovens que procuram conforto e salvação" (CNBB, 2006).

Segundo Guimarães (2002), em pesquisa realizada sobre juventude e educação, "os jovens apontam, ainda, a família, a igreja e a escola como as instituições da vida cotidianas mais importantes dentre as 18 apresentadas no questionário que foi formulado pela pesquisadora".

Aquino (2007) cita que "em discurso realizado aos arcebispos do Brasil, o papa João Paulo II afirmava que o futuro da igreja no Brasil depende em grande parte da consolidação da família e da formação dos jovens".

Para Castro (2013), ao considerar a influência do contexto para a análise da juventude, "pluraliza-se sua concepção e coloca em cena as intervenções de aspectos culturais, políticos e econômicos, que influenciam de forma heterogênea na construção do coletivo juvenil". Desse modo, a identidade social dos jovens possui estreita relação com os momentos históricos e com as instituições educacionais, familiares, religiosas e da sociedade civil (política, mídia e organizações sociais).

Segundo Groppo (2000):

...a juventude aparece como força transformadora da modernidade, com elementos dinâmicos de um tempo em constante mudança, independente do sentido "progressivista" ou "conservador" de sua atuação. Por isso, apresentam-se ora como contestadores da ordem vigente, ora como legitimadores dessa mesma ordem. Logicamente as mudanças impostas pela juventude não acontecem de um dia para noite, mas se processam a partir de seus questionamentos sobre a realidade. 
Fernandes e Pitta (2006) "salientam que nesse momento da vida, os jovens estão envolvidos com experiências estudantis, preocupados com trabalho, lazer e vida efetiva, e a religião, tende a não aparecer como fator prioritário".

Isso enfraquece o processo de transmissão da tradição religiosa, gerando declínio das instituições e crise nos compromissos religiosos. No caso da juventude, o efeito da secularização nos parece mais em evidência pela facilidade dos jovens em questionar e buscar novas possibilidades. Em consequência, a religião da juventude deixou de ser institucional para ser pessoal. "O jovem pós-moderno não se vê obrigado a continuar no mesmo percurso religioso dos pais, pois se percebe autônomo na configuração de sua forma de crer não vendo necessidade de estar preso a determinações e convenções religiosas" (OLIVEIRA, 2010).

Oliveira (2010) cita que:

As instituições religiosas devem repensar suas práticas e principalmente a forma em como suas mensagem são transmitidas aos diversos grupos que a compõem. Ademais, se acredita que haja necessidade de um ressignificar, não da palavra (Bíblia), mas da forma com que nos portamos e vivenciamos o evangelho no presente século.

A partir dos dados coletados, podemos selecionar alguns quesitos importantes que nos mostram principalmente a questão religiosa nas três principais religiões existentes no município de Santa Teresa. Podemos observar a grande quantidade de jovens que mudaram de procedimentos, após entrar para a igreja, mostrando a influência da igreja em sua formação social. A participação da igreja na mudança de conduta, na formação social, e no aprendizado, vai influir significativamente na formação social de nossos jovens. Participantes das igrejas, têm conhecimento de pessoas que mudaram o seu comportamento, após entrarem para alguma igreja. Os índices nos mostram que em toda igreja há pessoas que mudaram seu comportamento a partir de sua entrada, e que as igrejas têm executado esse trabalho de transformação do ser humano (Tabela 6).

Podemos observar que, nas três religiões estudadas, todas proporcionaram mudanças nas condutas dos jovens, após entrarem para a igreja, e não só os entrevistados citaram as mudanças, percebe-se que a grande maioria conhece adeptos que apresentaram mudanças em sua conduta ao entrar para alguma religião. Apontam ainda que, além de considerarem 
a contribuição efetiva da religião, na formação social, reconhecem que todas têm participação decisiva nessa formação, causando mudanças de procedimentos ao entrarem para a religião.

É visto que a religião possui grande importância no papel formador dos jovens, influenciando decisivamente na educação de seus filhos. Esses atributos citados mostram que a participação dos jovens, em qualquer religião, apresenta mudanças que classificam as religiões como de papel fundamental na formação social dos jovens, com contribuição decisiva para qualificar essa formação.

Tabela 6 - Dados sobre as religiões pesquisadas.

\begin{tabular}{lccc}
\hline Perguntas & $\begin{array}{c}\text { Católica } \\
(\%)\end{array}$ & $\begin{array}{c}\text { Espírita } \\
(\%)\end{array}$ & $\begin{array}{c}\text { Protestante } \\
(\%)\end{array}$ \\
\hline $\begin{array}{l}\text { Presenciou mudanças de conduta de jovens, após } \\
\text { entrar para a igreja }\end{array}$ & 78 & 77 & 90 \\
$\begin{array}{l}\text { Possui conhecimento de participante que mudou, } \\
\text { após entrar para a igreja }\end{array}$ & 88 & 89 & 79 \\
$\begin{array}{l}\text { Você acha que a igreja é a instituição que mais con- } \\
\text { tribui para a formação social do jovem }\end{array}$ & 40 & 49 & 75 \\
$\begin{array}{l}\text { Todas as religiões contribuem para a formação social } \\
\text { do jovem }\end{array}$ & 89 & 94 & 73 \\
$\begin{array}{l}\text { Houve mudanças de procedimentos, após entrar } \\
\text { para a igreja }\end{array}$ & 100 & 100 & 100 \\
$\begin{array}{l}\text { A igreja teve importância na sua formação social } \\
\text { A participação da igreja influenciou na educação } \\
\text { dos filhos }\end{array}$ & 100 & 100 & 100 \\
\hline
\end{tabular}

Considerando os resultados obtidos por meio da pesquisa, procuramos chegar a um resultado final, onde poderemos apresentar respostas quantitativas que possam se relacionar com o objetivo da pesquisa. Exibimos um quadro representativo dos principais dados obtidos na pesquisa de campo (Figura 1).

De acordo com os dados obtidos na pesquisa, podemos construir um gráfico representativo que estima o efeito que a religião pode ter na formação social de jovens. Consideramos para a pesquisa jovens que cursam o ensino médio nas escolas do município de Santa Teresa (Figura 2). 


\begin{tabular}{|l|l|}
\hline & Perguntas e Resultados \\
\hline A & Mostra que $95,7 \%$ acreditam que a igreja pode ajudar em alguma coisa. \\
\hline B & Mostra que $92,1 \%$ acreditam que a igreja pode mudar a vida de alguém. \\
\hline C & Mostra que $90,5 \%$ acreditam que a igreja pode conduzir os caminhos de alguém. \\
\hline D & Mostra que $94,6 \%$ acreditam que a igreja pode ajudar na boa formação dos jovens. \\
\hline E & $\begin{array}{l}\text { Mostra que } 100 \% \text { citam que houve mudanças de procedimentos, após entrarem } \\
\text { para a igreja. }\end{array}$ \\
\hline F & Mostra que 100\% citam que a igreja teve importância em sua formação social. \\
\hline G & $\begin{array}{l}\text { Mostra a média de } 99 \% \text { entre as três igrejas, onde citam que a igreja teve influên- } \\
\text { cia na educação que pretendem para seus filhos. }\end{array}$ \\
\hline H & Ponto médio dos valores observados. \\
\hline
\end{tabular}

Figura 1 - Quadro demonstrativo da figura 2.

Verificamos que a coluna do ponto médio na Figura 2 fica entre os percentuais de $90 \%$ e $100 \%$, sendo o ponto médio, PM $=96 \%$. De acordo com o observado, podemos considerar como "altíssima" a influência que a igreja possui na formação social dos jovens das escolas de ensino médio do município de Santa Teresa, ES., Brasil.

A Figura 3 nos mostra que qualquer que seja a linha religiosa dos alunos, qualquer que seja a prática religiosa na igreja ou no grupo religioso que frequentam, todas as igrejas influenciam de forma semelhante na formação social dos jovens que as frequentam.

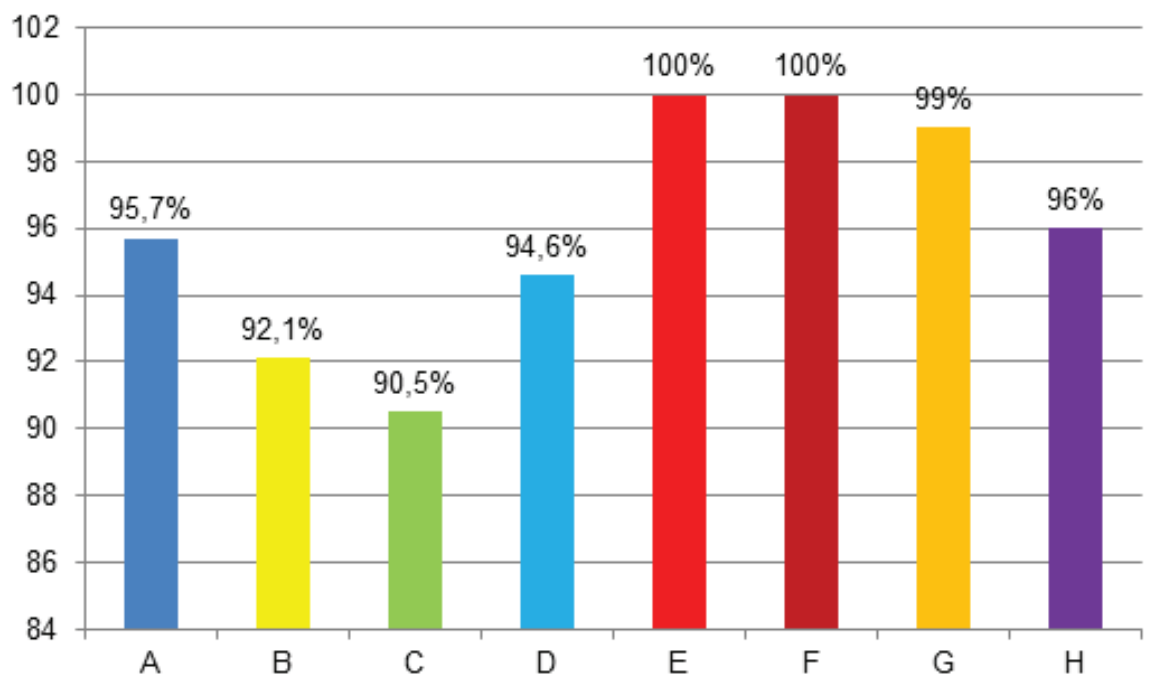

Figura 2 - Percentuais das principais influências que a igreja possui sobre os jovens. 
Observa-se na linha representativa da Figura 3, o ponto médio, PM $=85 \%$. Podemos considerar como "alta" a aceitação de que todas as linhas religiosas influenciam na formação social dos jovens.

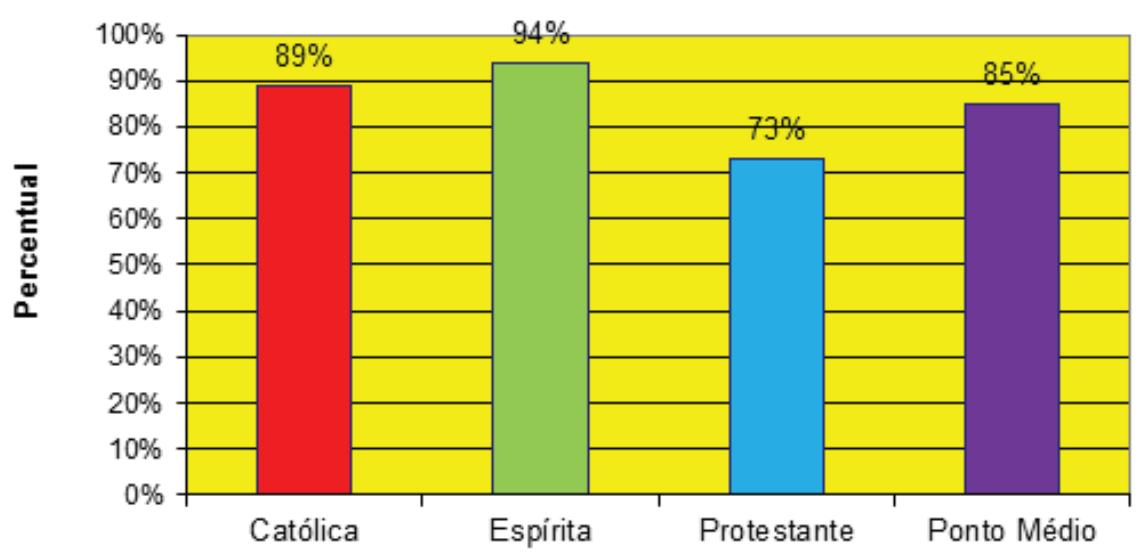

\section{Igrejas}

Figura 3 - Todas as igrejas contribuem para a boa formação dos jovens.

A escolha da religião também pode influenciar no desenvolvimento da formação social. Todas as religiões pregam a existência de um ente maior que interfere diretamente na vida de cada um. Fato que pode ser considerado quando ainda adolescente se queremos ou nos induzir a frequentar alguma religião.

Os resultados nos mostram que a escolha da religião não interfere na formação social do jovem, mas sim ter uma religião. Independentemente do local em que vivemos, temos resultados semelhantes. Nos diferentes países, podemos observar que a opção do adolescente é semelhante, e a liberdade de escolha parte do próprio jovem. Exemplificamos para tal os Estados Unidos, considerado a maior potência mundial. Segundo Smith \& Denton (2005):

Os Estados Unidos são uma terra de muitos credos, e os adolescentes praticam sua religião de várias formas. Logo que iniciam os estudos de história americana, as crianças aprendem que a liberdade religiosa e a separação entre igreja e Estado são alguns dos princípios norteadores do governo do país. Cada pessoa é livre para escolher e praticar sua religião. Muitos adolescentes tomam suas decisões influenciadas pela família. Alguns frequentam escolas administradas por grupos religiosos, e outros participam de programas após a 
escola ou nos fins de semana patrocinados pela igreja, sinagoga ou mesquita. Há ainda pessoas que preferem não praticar nenhuma religião.

Observe que os EUA., um país desenvolvido, pregam a liberdade religiosa, porém de alguma forma o jovem aprende o que é religião, e pode escolher a qual pertencer.

De acordo com os resultados da pesquisa, podemos observar que a atuação da religião é fundamental para a construção do caráter, personalidade, conduta e outros atributos que constroem a formação social do jovem. Pelas respostas obtidas ao longo do texto, percebe-se que os ensinamentos religiosos atuam diretamente na formação da conduta daqueles que a frequentam, e que os jovens que possuem uma formação religiosa no período juvenil apresentam uma formação social compatível com as exigências da sociedade contemporânea.

\section{Considerações finais}

A igreja tem uma influência altíssima na formação social dos jovens que a frequentam, atuando de forma marcante em seu relacionamento pessoal, sua conduta, comportamento, atitudes e valores praticados no âmbito da família, sociedade e escola.

Independentemente da linha religiosa, todas atuam de forma positiva na formação social do jovem de que o importante é ter uma religião, frequentar e aderir aos seus preceitos de forma concreta. Ficou comprovado a aceitação de que todas as linhas religiosas influenciam na formação social dos jovens, e que a igreja, como instituição, está entre as grandes fontes de promulgação de princípios na participação da formação social dos jovens.

\section{Referências}

AQUINO, F. Documentos da Igreja. SP: Editora Cléofas, 2007.

CASTRO, G. Jóvenes contemporáneos. La historia y la subjetividad. Revista Argentina de Estudios de Juventud, La Plata, v. 1, n. 7, p. 01-23, 2013.

CNBB. Evangelização da Juventude, 3. ed. São Paulo: Ed. Paulus, 2006.

DINIZ, R. N. Uma religiosidade móbile, Revista eletronica de Ciencias Sociais, Pb, 1999.

FERNANDES, S. R. A.; PITTA, M. Mapeando as rotas do trabalho religioso no Brasil. Religião e Sociedade, v. 26, Rio de Janeiro, RJ, 2006. 
GROPPO, L. A. Juventude: ensaios sobre sociologia e história das juventudes modernas. Rio de Janeiro: DIFEL, 2000.

GUIMARÃES, M. T. C. Juventude, educação e campo simbólico, Revista Brasileira de Estudos da População, Goiás, v. 19, n. 2, 2002.

IBGE. Número de católicos cai e aumenta o de evangélicos, espíritas e sem religião, 2010. Disponível em:

http: / / censo2010.ibge.gov.br/ noticias-censo.html?view $=$ noticia\&id $=3 \& i d n o t i c i a=2170 \&$ bus$\mathrm{ca}=1 \& \mathrm{t}=$ censo-2010. Acesso em: 12 fev. 2017.

INCAPER. Planejamento e programação de ações para Santa Teresa. Programa de assistência técnica e extensão rural PROATER, Secretaria de Agricultura, 2011.

NOVAES, R. Os jovens “sem religião": ventos secularizantes, "espírito de época” e novos sincretismos, Estud. Avançados, v. 18, n. 52, São Paulo, 2004.

OLIVEIRA, W. C. Juventude e religião no século XXI: a crise dos compromissos religiosos. Revista de Ciências Humanas e Letras das Faculdades Integradas da Fama, v. 2, n. 1, 2010.

PORTAL SUA ESCOLA. As cinco religiões do Brasil, 2016. Disponível em: http://portalsuaescola.com.br/5-religioes-brasileiras/. Acesso em: 3 fev. 2017.

SMITH, C. \& DENTON, M. L. Soul Searching: The Religious and Spiritual Lives of American Teenagers (Em Busca da Alma: A Vida Religiosa e Espiritual dos Adolescentes Americanos). Nova York: Oxford University Press, 2005.

Submetido em: 23-4-2017

Aceito em: 25-11-2018 